\title{
O CONCEITO DE CONSCIÊNCIA NO PROJETO DE UMA PSICOLOGIA DE FREUD E SUAS IMPLICAÇÕES METAPSICOLÓGICAS
}

\author{
Richard Theisen SIMANKE ${ }^{1}$ \\ Fátima Siqueira CAROPRESO
}

- RESUMO: No Projeto de uma psicologia, de 1895, está exposta uma ampla reflexão sobre o conceito de consciência, a qual, embora apresente algumas dificuldades, permite esclarecer como a relação entre a consciência, a representação e a linguagem era pensada por Freud nesse momento. O objetivo deste artigo é circunscrever o sentido da noção de consciência presente no Projeto de uma psicologia e discutir algumas de suas implicações para o modo como a consciência será abordada nos desenvolvimentos posteriores da metapsicologia freudiana.

- PALAVRAS-CHAVE: Freud; metapsicologia; representação; consciência; linguagem.

No Projeto de uma psicologia - redigido por Freud em 1895, mas publicado apenas em 1950, onze anos após sua morte - vários conceitos freudianos são pela primeira vez esboçados, alguns dos quais não voltam a receber tratamento tão sistemático na obra posterior de Freud. Este é o caso do conceito de consciência, que é alvo de uma ampla reflexão no Projeto..., na verdade, a mais extensa de toda a obra freudiana. $\mathrm{O}$

1 Professor do Departamento de Filosofia e Metodologia das Ciências e do PPG em Filosofia da Universidade Federal de São Carlos (UFSCar). Rodovia Washigton Luís, km 235, São Carlos, SP, CEP: 13565-905. E-mail: drts@power.ufscar.br

2 Doutoranda no Programa de Pós-Graduação em Filosofia da Universidade Federal de São Carlos (UFSCar). Rodovia Washigton Luís, km 235, São Carlos, SP, CEP: 13565-905. E-mail: fatimacaropreso@uol.com.br 
objetivo deste artigo é circunscrever o sentido da noção de consciência formulada por Freud em 1895 e comentar algumas das suas implicações para a avaliação de sua abordagem posterior no interior do projeto metapsicológico, tal como se encontra formulado em Freud. Tendo isso em vista, as considerações que se seguem constam de: 1) uma exposição geral, ainda que esquemática, das principais noções que compõem a teoria psicológica apresentada por Freud no Projeto...; 2) uma exposição e discussão da concepção de consciência aí esboçada; 3) alguns comentários, mais exploratórios do que conclusivos, sobre certos desdobramentos dessa concepção no âmbito da reflexão metapsicológica posterior.

\section{O aparelho neuronal}

É necessário, então, iniciar com uma breve exposição geral das teses do Projeto, tendo em vista apenas os objetivos do presente trabalho. A proposta inicial do Projeto é fornecer uma psicologia científico-naturalista, segundo a qual os processos psíquicos normais e patológicos seriam explicados a partir de dois postulados principais: a "quantidade"(Q) e o "neurônio"(N). Ele desenvolve a idéia de um "aparelho neuronal", cujo funcionamento e estrutura seriam determinados, inicialmente, pelo "princípio de inércia", isto é, por uma tendência a descarregar toda a quantidade que alcançasse o aparelho. O objetivo manifesto é explicar todos os processos psíquicos mecanicamente, mas, em algumas ocasiões, na impossibilidade de cumprir essa meta, Freud recorre a justificativas biológicas.

O primeiro pilar da teoria, a noção de "quantidade", é definida como algo que diferencia a atividade do repouso e que está submetido à lei geral do movimento. A natureza dessa quantidade não é especificada. Há afirmações, no Projeto... e em outros textos da mesma época (Freud 1894, por exemplo) que permitem supor que Freud atribuísse uma natureza elétrica à quantidade; esta é a interpretação de Pribram e Gill (s./d.) que neste ponto discordam frontalmente de Strachey (1975). Mas, em outras passagens, Freud parece trabalhar com uma concepção mais hidráulica da quantidade, valendo-se de uma linguagem que está mais próxima, pelo menos metaforicamente, da mecânica dos fluidos, de modo que a questão permanece indecidida. O segundo postulado principal, o "neurônio", é concebido como a unidade material do sistema nervoso. Os neurônios seriam, por hipótese, estruturalmente idênti- 
Cos, anatomicamente independentes uns dos outros e entrariam em contato entre si por mediação de tecido não neuronal. Eles receberiam quantidade através dos prolongamentos celulares (dendritos) e a emitiram través dos cilindros de eixo (axônios). Deste modo, sua estrutura estaria de acordo com a tendência fundamental do aparelho, pois favoreceria a descarga da quantidade, funcionando como um sistema reflexo em miniatura.

A tendência primordial do aparelho seria anular todo o aumento quantitativo, isto é, manter o nível de quantidade no aparelho idêntico a zero. Esta pode ser entendida como uma tendência a evitar o desprazer, pois Freud identifica o aumento da excitação com o desprazer e a sua diminuição com o prazer. O surgimento da quantidade endógena decorrente das necessidades vitais - imporia, contudo, uma modificação a essa tendência primária. Se o sistema recebesse apenas quantidade de origem exógena, seria possível, em princípio, a partir do movimento reflexo, descarregá-la totalmente e, assim, mantê-lo afastado de todo aumento quantitativo. Mas tal sistema, além de quantidade exógena, receberia também quantidade endógena, e esta não poderia ser suprimida através do mecanismo reflexo unicamente. Embora os movimentos reflexos funcionem como um meio de descarga para a quantidade endógena, eles não são capazes de anular a fonte de estimulação, como o fazem em relação à quantidade exógena, ou seja, eles não permitem, nesse caso, a fuga de estímulo. A anulação de uma fonte interna de estimulação dependeria de uma atuação mais complexa sobre o mundo, como, por exemplo, a obtenção de alimento, no caso da fome. Seria necessário o que Freud chama de uma "ação específica" para que a estimulação endógena pudesse cessar e, devido à sua complexidade, a execução dessa ação teria como condição um acúmulo de quantidade no aparelho, o que imporia uma modificação na sua tendência fundamental. Em vez de manter o nível de quantidade igual a zero, a tendência dominante passaria a ser mantê-lo constante no nível mínimo necessário. Assim, o princípio de inércia daria lugar a uma "tendência à constância". Esta última não se oporia ao princípio de inércia; ao contrário, atuaria em seu favor permitindo que a quantidade endógena fosse, de fato, descarregada adequadamente.

O aparelho neuronal seria composto por três sistemas distintos de neurônios: o sistema $\phi$, cuja função seria receber a quantidade oriunda da periferia do sistema nervoso e transmiti-la, enfraquecida e fracionada, ao sistema vizinho $\psi$; o sistema $\psi$, que seria um sistema de memória, onde se formariam as representações; e o sistema $\omega$, que consistiria 
na base material da consciência. Tais sistemas não se diferenciariam uns dos outros devido à estrutura dos neurônios que os compõem - uma vez que Freud trabalha com a hipótese de que todos os neurônios são estruturalmente idênticos -, mas sim devido ao modo distinto de ação da quantidade em cada um deles. Entre os neurônios haveria "barreiras de contato", as quais ofereceriam uma certa resistência à passagem da excitação de um neurônio para outro, fazendo com que apenas as quantidades cuja intensidade fosse superior à da resistência dessas barreiras conseguissem passagem. Quando isto ocorresse, a barreira de contato seria "facilitada", fazendo com que numa segunda ocupação dos neurônios correspondentes a resistência encontrada fosse menor. A facilitação diferenciada das barreiras de contato faria com que se constituíssem caminhos preferenciais no interior do aparelho, os quais possibilitariam a memória. Mas apenas no sistema $\psi$ as barreiras de contato seriam capazes de oferecer resistência à passagem da excitação; no sistema $\phi$, as quantidades recebidas possuiriam intensidade superior à da resistência das barreiras de contato e, por isso, nesse sistema, tais barreiras estariam totalmente facilitadas, não exercendo, assim, nenhuma função; o sistema $\phi$ seria, por isso, completamente permeável à quantidade. Já em $\psi$ - que receberia quantidade exógena via $\phi-$, as ocupações seriam menos intensas, devido ao fato de que a estrutura ramificada de $\phi$ faria com que a corrente excitatória se distribuísse por diversos caminhos, passando a $\psi$ em vários pontos. Assim, em vez de ser ocupado muito intensamente em um ponto, o sistema de memória seria ocupado em vários pontos, com uma intensidade menor. ${ }^{3} \mathrm{~A}$ quantidade que alcançasse $\psi$ possuiria intensidade inferior à da resistência das barreiras de contato e, por isso, para conseguir passagem, uma mesma barreira teria que ser ocupada a partir de dois ou mais neurônios simultaneamente, o que faria com que se constituíssem ali caminhos diferenciados. Um grupo de neurônios ocupados cujas barreiras de contato estivessem facilitadas entre si constituiria uma representação. $\mathrm{Na}$ ausência da ocupação, a representação continuaria existindo potencialmente, dado que as facilitações assegurariam a possibilidade de recorrência do mesmo processo, isto é, assegurariam a possibilidade do res-

3 Aqui teríamos uma primeira explicação, mecânica e topográfica, da relação inversa entre intensidade e complexidade que parece se impor na concepção freudiana do aparelho neuronal ou psíquico. Mais adiante, como se verá, Freud insistirá em que a consciência depende, entre outras coisas, da diminuição da intensidade dos processos no sistema $\psi$. Pode-se, talvez, inferir daí que ela dependa igualmente de um aumento concomitante da complexidade da organização desses processos 
surgimento da representação. O sistema $\psi$, no entanto, seria ocupado também a partir do interior do organismo, pois estaria diretamente ligado a este. O modo de ação da quantidade endógena seria diferente do da exógena e, por esse motivo, Freud é levado a dividir o sistema $\psi$ em dois: " $\psi$ do manto", que receberia quantidade exógena via $\phi$ e " $\psi$ do núcleo" que receberia quantidade endógena diretamente do interior do organismo. As quantidades endógenas seriam muito pouco intensas e, para conseguir facilitar as barreiras de contato que separam $\psi$ do manto do interior do organismo, elas teriam que se somar progressivamente. Quando conseguissem ingressar em $\psi$ do núcleo, elas adquiriam expressão psíquica, ou seja, dariam origem a representações. ${ }^{4}$

O conjunto de ocupações de $\psi$ do núcleo constituiria a base do "eu". Este seria o portador do armazenamento de quantidade necessário para a satisfação das necessidades vitais, quantidade esta que seria por ele utilizada para direcionar os processos associativos, de modo que estes alcançassem as condições necessárias para tal satisfação e impedissem a produção de desprazer. O eu atuaria através de "ocupações laterais", isto é, ocupando os neurônios adjacentes aos ocupados a partir de $\phi$ e deslocando, assim, o curso da corrente excitatória. Ele teria acesso a todas as facilitações de $\psi$ do manto e, por isso, seria composto por uma parte constante - as ocupações do núcleo - e uma parte variável as ocupações ocasionais do manto, que teriam a finalidade de ali alterar o curso associativo. Segundo Freud, a quantidade do eu estaria em "estado ligado", ou seja, na passagem da excitação de um neurônio para outro, parte dela seria retida no primeiro, de modo que os neurônios permaneceriam permanentemente ocupados. A excitação em estado ligado, no entanto, só passaria a existir após a inibição do modo de associação primário, o qual se caracterizaria pelo livre fluxo da quantidad pelos neurônios, sem a retenção de nenhuma parte da excitação. Essa inibição seria condicionada por uma regra biológica - a "defesa primá-

4 Pode haver uma certa controvérsia quanto ao lugar onde se dá a expressão psíquica dos estímulos somáticos. É claro que a plena expressão psíquica das quantidades endógenas só se dá quando os processos do núcleo se associam com as representações de objeto e, depois, com as representações de palavra que se constituem em $\psi$ do manto. Contudo, entendemos que a primeira e mais originária expressão psíquica do somático se dá já com a ocupação do núcleo, uma vez que $\psi$ é o sistema de representação do aparelho neuronal e $\psi$ do núcleo é, evidentemente, uma parte deste sistema. De certo modo, os processos do núcleo equiparam-se, a nosso ver, ao que Freud depois denominou de representante de pulsão (Triebrepräsentanz) - ou, mais precisamente, ao componente representacional do representante de pulsão (o outro componente é o afeto) - tal como estas noções são desenvolvidas nos artigos metapsicológicos. 
ria" -, segundo a qual a ocupação de representações que geram desprazer tende a ser evitada. Esse condicionamento ocorreria devido ao desprazer produzido nos processos psíquicos primários que decorrem do que Freud chama de "vivência de satisfação", vivência esta que seria estruturante do modo de funcionamento normal do aparelho.

Vejamos como a vivência de satisfação e suas conseqüências são descritas por Freud. Na primeira vez em que o recém-nascido sentisse fome, isto é, na primeira ocupação de $\psi$ do núcleo, tal ocupação levaria a respostas reflexas, como o grito, o choro e a agitação motora, as quais consistem na única forma de eliminação da quantidade que o bebê possui. Tal reação, embora não seja capaz de eliminar o desprazer, uma vez que a fonte de estimulação não seria anulada, funcionaria como um meio de comunicação entre a criança e o adulto, pois faria com que este atentasse para o estado de carência do bebê. Quando o adulto executasse a ação específica - por exemplo, quando a mãe oferecesse o seio à criança - esta, através de ações reflexas, realizaria os movimentos necessários para a alimentação (a sucção, por exemplo) e, assim, a recepção de estímulos internos cessaria, fazendo com que o desprazer desaparecesse. É esta experiência que é chamada por Freud de "vivência de satisfação". Como conseqüência de tal vivência, ocorreriam três coisas em $\psi$. Em primeiro lugar, o desprazer decorrente da ocupação do núcleo de $\psi$ cessaria; em segundo lugar, constituir-se-ia uma representação do objeto externo, cuja percepção fora simultânea à experiência de satisfação; e, em terceiro, formar-se-ia uma representação do movimento reflexo executado. ${ }^{5}$ Entre essas duas representações de $\psi$ do manto e os neurônios nucleares se estabeleceria uma facilitação, devido ao fato das primeiras se terem constituído simultaneamente à ocupação de $\psi$ do núcleo. Uma vez estabelecidas essas facilitações, quando o estado de excitação no núcleo reaparecesse, o processo excitatório seguiria o caminho por elas definido e ocuparia a representação de $\psi$ do manto. Esta tendência para ocupar as representações de objeto em $\psi$ do manto é o que Freud chama de "desejo". ${ }^{6}$ Neste caso, não havendo nenhuma inibi-

5 Todos os movimentos dariam origem a excitações sensoriais que constituiriam imagens de movimento em $\psi$, segundo Freud.

6 O desejo seria uma tendência para ocupar a representação de um objeto, e a ocupação desta representação consistiria em uma "realização de desejo". Na segunda ocorrência do processo não haveria apenas uma necessidade, mas também um desejo, uma vez que o estado de carência já teria se associado à representação de um objeto, e o processo psíquico resultante, então, visaria especificamente à sua ocupação. 
ção, a ocupação da representação de objeto devido à animação de desejo seria muito intensa, de modo que seriam despertados "signos de qualidade", 7 como se se tratasse de uma percepção externa, ou seja, ocorreria uma alucinação. Em conseqüência dessa alucinação, a ação reflexa - no caso, a sucção - seria executada e, nessas condições, provocaria uma frustração. O recém-nascido se encontraria, assim, num estado de "desamparo". Desta forma, para a sobrevivência do indivíduo, seria necessário haver uma alteração nessa tendência primária do processo associativo de seguir unicamente o caminho mais bem facilitado, de forma que a representação de desejo não fosse mais tão intensamente ocupada e, assim, permitisse ao eu diferenciar entre uma rememoração e uma percepção e, com isto, evitasse a ocupação das representações de movimento na ausência do objeto na realidade. Em suma, para a sobrevivência do indivíduo seria necessária a substituição do modo primário de funcionamento do aparelho - do "processo primário", que se caracterizaria pelo fluxo livre da quantidade através dos neurônios - por um modo secundário de funcionamento - pelo "processo secundário", que se caracterizaria pela retenção de uma parte da quantidade nos neurônios. Freud explica a inibição do processo primário a partir do que ele chama de "primeira regra biológica", a "defesa primária", que consistiria numa tendência a não ocupar as representações que geram desprazer. O desprazer decorrente da ocupação de certas representações condicionaria o eu a não mais ocupá-las. Como no ressurgimento da fome, após a vivência primária de satisfação, a ocupação muito intensa da representação desejada e das imagens motoras a ela associadas provocaria uma intensificação do desprazer, a defesa primária faria com que o eu, primeiro, não mais ocupasse as representações de movimento constituídas na vivência de satisfação e, depois, faria com que ele não mais ocupasse a representação de desejo tão intensamente. Assim, os signos de qualidade não seriam mais fornecidos na ausência do objeto na realidade e, então, quando surgissem, eles atuariam como um sinal de que o objeto desejado está presente e de que os movimentos necessários para a obtenção da satisfação podem ser executados; o desamparo, com isso, seria superado. Desse modo, o condicionamento do eu pela primeira regra biológica conduziria à inibição do processo primário, marcando, assim, a passagem do processo primário para o secundário,

7 Os signos de qualidade é que possibilitariam a consciência de uma representação. Voltaremos a essa questão adiante, na discussão da concepção de consciência presente no Projeto 
a qual coincidiria com a substituição da tendência à inércia pela tendência à constância. Esta inibição faria com que uma certa quantidade fosse retida no núcleo - isto é, a excitação livre seria ligada - assegurando, desta forma, a manutenção da reserva necessária para que o eu pudesse influenciar os processos associativos, de modo a evitar a produção de desprazer e a propiciar a satisfação das necessidades vitais.

Haveria, como foi dito, um terceiro sistema de neurônios - o "sistema $\omega$ - que estaria relacionado com a consciência. Mas, antes de analisarmos as características desse sistema, é necessário ainda esclarecer como a relação da consciência com os demais processos psíquicos é pensada no Projeto.

\section{A relação entre o psíquico e a consciência no Projeto}

No Projeto (1950), Freud estende a noção de psíquico em relação à de consciência. No texto "Sobre a concepção das afasias" (1891), ele havia mantido a identificação do psíquico ao consciente e nos textos sobre as neuroses do período entre 1891 e 1895, embora reconheça ser necessário atribuir os sintomas neuróticos a processos inconscientes, ele não chega a afirmar cabalmente que tais processos são de natureza psíquica. No Projeto, pela primeira vez, a possibilidade de um psíquico inconsciente é claramente aceita:

Temos tratado os processos psíquicos como algo que poderia carecer deste conhecimento através da consciência, que existe independente de uma tal consciência (...) Se não nos deixarmos desconcertar por isso, segue-se dessa pressuposição que a consciência não proporciona conhecimento nem completo, nem confiável dos processos neuronais; estes últimos têm que ser considerados, antes de tudo e em toda sua extensão, como inconscientes e têm que ser inferidos como as outras coisas naturais. (Freud, 1895/1950, p. 400)

A consciência é concebida como algo paralelo a apenas uma parte dos processos psíquicos inconscientes. Os processos que ocorressem no sistema $\omega$ teriam paralelos conscientes, ao contrário dos demais processos. Ao comentar a relação da sua teoria da consciência com as demais, Freud afirma:

Segundo uma teoria mecanicista avançada, a consciência é um mero acessório dos processos fisiológico-psíquicos, cuja supressão não alteraria 
nada no decurso psíquico. Segundo outra doutrina, a consciência é o lado subjetivo de todo acontecimento psíquico, portanto inseparável do processo anímico fisiológico. Entre ambas situa-se a doutrina aqui desenvolvida. Consciência é, aqui, o lado subjetivo de uma parte dos processos físicos no sistema nervoso - isto é, dos processos $\omega$ - e a supressão da consciência não deixa inalterada o acontecimento psíquico, mas inclui em si a supressão da contribuição de $\omega$. (Freud, 1895/1950, p. 404)

Freud propõe que os processos psíquicos inconscientes são processos nervosos e que, por isso, eles devem ser abordados de uma perspectiva científico-naturalista. Como consistem em processos físicos envolvendo neurônios e quantidades, o psíquico inconsciente estaria dentro do campo da ciência natural. Já o psíquico consciente estaria excluído desse campo:

Até aqui, não se levou em conta para nada que toda teoria psicológica, além das (außer den) operações do lado científico-naturalista, tem ainda que satisfazer uma grande exigência. Ela deve explicar-nos aquilo que conhecemos, da forma mais enigmática, através de nossa "consciência" (...). (Freud, 1895/1950, p. 400, grifos nossos)

A afirmação de que os fenômenos conscientes estão "além das operações do lado científico-naturalista" sugere que está sendo atribuída a tais fenômenos uma natureza distinta da dos demais processos psíquicos, o que teria como conseqüência a proposição de uma cisão dentro do campo da psicologia entre uma psicologia do inconsciente - que seria uma ciência natural - e uma teoria da consciência - que requereria uma outra espécie de abordagem, que, contudo, não é especificada. Esta idéia é retomada mais claramente ainda por Freud no "Esboço de psicanálise" de 1938. Nesse texto, ele retoma a idéia de concomitância entre o psíquico consciente e o inconsciente:

...esses processos conscientes não formam séries sem lacunas, fechadas em si mesmas, de modo que não haveria outra alternativa a não ser adotar a suposição de uns processos físicos ou somáticos concomitantes do psíquico, aos quais parece necessário atribuir uma perfeição maior do que às séries psíquicas, pois alguns deles têm processos conscientes paralelos e outros não. Isso sugere pôr o acento, na psicologia, sobre esses processos somáticos, reconhecer neles o psíquico genuíno e buscar uma apreciação diversa para os processos conscientes. (Freud, 1938, p.156, grifos nossos)

Freud acrescenta que essa posição permite tratar parte da psicologia como uma ciência natural: 
Enquanto a psicologia da consciência nunca saiu daquelas séries lacunares, que evidentemente dependem de outra coisa, a concepção segundo a qual o psíquico é em si inconsciente permite configurar a psicologia como uma ciência natural entre as outras. (Freud, 1938, p.156)

Apesar de considerar a consciência como algo paralelo a uma parte dos processos neuronais, Freud tenta, no Projeto, estabelecer as condições materiais da consciência, ou seja, as características dos processos físicos concomitantes a ela, que tornariam inteligível sua possibilidade. Para tanto, ele introduz um terceiro sistema de neurônios - o sistema $\omega$ - do qual nos ocuparemos a partir de agora.

\section{O sistema $\omega$}

Freud argumenta que é necessário introduzir um terceiro sistema de neurônios para explicar a produção das sensações ou das qualidades conscientes, porque tais sensações não poderiam se originar em $\psi$, uma vez que este sistema é responsável pela rememoração, e esta é desprovida de qualidade; elas também não poderiam se originar em $\phi$, porque se sabe que a consciência está relacionada com os níveis mais elevados do sistema nervoso, e não poderia originar-se no mundo externo, pois neste haveria apenas massas em movimento. Então, é necessário postular um terceiro grupo de neurônios - os quais constituiriam o sistema $\omega$-, cujos estados de excitação seriam responsáveis pela consciência, conclui Freud. Este sistema estaria conectado apenas a $\psi$; portanto, a ordem dos sistemas seria: $\phi \psi \omega$.

Uma vez que as quantidades em $\psi$ seriam pouco intensas - de modo que apenas a ocupação simultânea de mais de um neurônio fosse capaz de facilitar as barreiras de contato, ou seja, de modo que tal sistema permanecesse parcialmente impermeável - e que $\omega$ poderia ser ocupado apenas a partir de $\psi$, a permeabilidade que caracteriza a consciência, isto é, o fato de que o sistema por ela responsável deve, como a percepção, apresentar sempre as mesmas capacidades receptivas, o que tem como condição a ausência de traços permanentes, essa permeabilidade, enfim, deveria resultar de algo diverso da intensidade da quantidade, pois esta seria ainda menos intensa do que aquela que alcança $\psi$ e, deste modo, incapaz de facilitar completamente as barreiras de contato. Isso levou Freud a introduzir um novo elemento na teoria: 
Vejo apenas uma saída: revisar a suposição fundamental sobre o decurso de Q' $\eta$. Até agora considerei este último apenas como transferência de Q' $\eta$ de um neurônio para outro. Mas ele deve ter ainda um caráter de natureza temporal, pois também aos outros movimentos de massa do mundo externo a mecânica dos físicos atribuiu esta característica temporal. Resumidamente, eu a denomino o período. Assim, suporei que toda resistência das barreiras de contato vale apenas para a transferência de $\mathrm{Q}$, mas que o período do movimento neuronal se propaga sem inibição em todas as direções, como um processo de indução por assim dizer. (Freud, 1895/1950, p. 402)

Então, os neurônios $\omega$ seriam permeáveis ao período, não à quantidade, e a isto se deveria a permeabilidade que caracteriza a consciência. Mas apenas o surgimento das qualidades sensoriais dependeria do período; as sensações de prazer e desprazer - que junto com as qualidades sensoriais formariam a classe das sensações conscientes - resultariam diretamente da ocupação de $\omega$ por quantidade. Segundo Freud, prazer e desprazer seriam conseqüências, respectivamente, da diminuição e do aumento do nível de quantidade em $\omega$. Haveria um limiar acima do qual a ocupação de $\omega$ produziria desprazer e um limiar abaixo do qual ela produziria prazer. Entre esses dois limiares, $\omega$ permaneceria sensível ao período:

(...) os neurônios $\omega$, com uma certa [potência de] ocupação, apresentam um nível ótimo para receber o período do movimento neuronal; com uma ocupação mais forte dão como resultado desprazer; com uma mais fraca, prazer, até que a capacidade de recepção desaparece com a falta de ocupação. (Freud, 1895/ 1950, p. 405)

O surgimento das qualidades sensoriais estaria, portanto, relacionado ao período. Essa hipótese adotada por Freud, no entanto, apresenta alguns problemas que requerem solução. Se a afecção dos neurônios pelo período consiste na base material da produção de qualidades sensoriais, por que apenas em $\omega$ esta surgiria? Se o período é uma propriedade da quantidade e se esta antes de chegar a $\omega$ deve passar necessariamente por $\phi$ e por $\psi$, por que as sensações conscientes não se originam a partir da ocupação destes sistemas? Freud procura responder a essa questão dizendo que o período em $\psi$ é monótono, por isso não haveria ali qualidades sensoriais, uma vez que estas não dependeriam apenas do período, mas das diferenças no período. Ele afirma que essas diferenças no período resultariam do fato dos órgãos sensoriais agirem como filtros, dando passagem apenas para estímulos com períodos específicos e que tal diferença seria transmitida dos órgãos sensoriais para 
$\phi$, deste para $\psi$ e daí para $\omega$. Sendo assim, um processo que tivesse origem apenas em $\psi$ (a rememoração, por exemplo) não faria surgir a qualidade sensorial, uma vez que a ausência de diferenças no período da excitação própria deste sistema privaria a qualidade de sua base física. ${ }^{8}$ Ao contrário, um processo oriundo da recepção de estímulos externos, que se propagasse de $\phi$ para $\psi$ e daí para $\omega$, traria consigo as variações do período que seriam decodificadas em $\omega$ como qualidades sensoriais.

Freud diferencia a produção de qualidades sensoriais da percepção consciente destas qualidades. Para que elas fossem percebidas pelo sujeito, não bastaria o seu surgimento, pois só quando o eu ocupasse os "signos de qualidade" fornecidos por $\omega$ à $\psi$, uma representação seria percebida. Essa hipótese dos signos de qualidade é uma das mais obscuras do Projeto. Freud introduz essa noção para explicar como seria possível a discriminação entre uma percepção e uma rememoração. Inicialmente, ele afirma que as representações constituídas em $\psi$ a partir de $\phi$ despertariam signos de qualidade e que estes signos permitiriam a diferenciação entre uma representação ocupada por quantidade de origem endógena - uma rememoração - e uma representação ocupada por quantidade exógena - uma percepção. Mas logo após introduzir esta hipótese, ele conclui que os signos de qualidade, em vez de explicarem esta discriminação, explicam a confusão entre essas duas coisas. A confusão entre percepção e rememoração, isto é, a alucinação, resultaria do fato de que não só no caso de ocupações oriundas de $\phi$, mas também de ocupações muito intensas oriundas de $\psi$, $\omega$ forneceria signos de qualidade. Freud, então, reconheceu que é necessário atribuir a distinção acima a um outro fator, o que o levou a formular a hipótese de que é o condicionamento do eu pela regra biológica da defesa, como comentamos anteriormente, que permite a discriminação em questão.

Mas, o que seriam, afinal, os signos de qualidade? Seriam notícias de eliminação da excitação de $\omega$, diz Freud:

(...) uma percepção, segundo minhas pressuposições, sempre excita $\omega$ e produz assim signos de qualidade. Dito de forma mais precisa, ela excita consciência em $\omega$ (consciência de uma qualidade), e a descarga da excitação $\omega$, [como] toda descarga, fornecerá uma notícia para $\psi$, que é justamente o signo de qualidade. (Freud, 1895/1950, p. 451)

8 Freud argumenta que a recepção das quantidades endógenas, que ocupam $\psi$, não se dá através de órgãos sensoriais terminais, como acontece com a quantidade exógena. Como são esses órgãos que atuam como filtros para os períodos capazes de ser percebidos em $\omega$, essa é mais uma razão para que processos originados exclusivamente em $\psi$ sejam desprovidos de qualidade. 
Em que consistiria a eliminação de $\omega$ ? Na descarga de quantidades por meio de movimentos:

Se se apresenta a consciência por meio dos neurônios $\omega$, isto tem várias conseqüências. Estes neurônios têm que ter uma descarga, por pequena que ela possa ser, e tem que existir um caminho para preencher os neurônios $\omega$ com Q' $\eta$ no ínfimo montante necessário. A descarga vai, como todas, para o lado da motilidade, no que se deve assinalar que, na circulação motora, perde-se evidentemente todo caráter qualitativo, toda especificidade do período. (Freud, 1895/1950, p.404)

Então, se os signos de qualidade são notícias em $\psi$ da eliminação da excitação $\omega$, eles só poderiam ser representações de movimento e tais representações não se diferenciariam em nada das demais representações de movimento que se constituem em $\psi$, pois, como Freud mesmo afirma, na via motora a qualidade desapareceria. Dessa forma, se a consciência de uma representação perceptiva depende da ocupação pelo eu dos signos de qualidade a ela correspondentes e se tais signos são representações de movimento, qual seria a função do sistema $\omega$ ?

Freud reconhece a problematicidade dessas idéias formuladas para explicar a base material da consciência e argumenta que isso não representa um impedimento para a continuação da teoria:

Apenas através dessas suposições complicadas e pouco intuitivas foi-me possível, até agora, incluir os fenômenos da consciência na estrutura da psicologia quantitativa. Não cabe, evidentemente, tentar uma explicação sobre como processos excitatórios nos neurônios $\omega$ trazem consigo consciência. Trata-se apenas de fazer corresponder propriedades da consciência conhecidas por nós com processos de alteração paralela nos neurônios $\omega$. Por outro lado, isso não vai mal no detalhe. (Freud, 1895/1950, p. 403)

A atividade consciente, embora restrita em relação à amplitude total do psiquismo, exerceria um papel não desprezível na vida psíquica: "a supressão da consciência não deixa inalterado o acontecimento psíquico, mas inclui em si a supressão da contribuição de $\omega^{\prime \prime}$, diz Freud (1895/1950, p. 404). Os signos de qualidade fornecidos pelo sistema $\omega$ é que tornariam possível tanto o acesso aos objetos necessários para a satisfação das necessidades vitais como a fuga dos objetos que geram desprazer, ou seja, tais signos seriam indispensáveis para a sobrevivência do sujeito.

Até aqui comentamos apenas o modo como Freud concebe os processos neuronais relacionados à consciência perceptiva, mas haveria ainda uma segunda forma de consciência intermediada pela linguagem, que consideraremos a seguir. 


\section{A relação entre a consciência e a linguagem}

Freud atribui a possibilidade de rememoração de uma representação à associação desta a representações de palavras. Ele argumenta que, uma vez que a consciência depende do despertar de signos de qualidade e que estes últimos provêm de percepções, para que uma representação ocupada pelo eu, e não a partir de $\phi$, se tornasse consciente seria necessário que, de alguma forma, ela produzisse uma percepção. Ele, então, conclui que um dos componentes da "representação de palavra" - a imagem cinestésica - é que possibilitaria isto. Como os movimentos produzem percepções, a ocupação da imagem cinestésica da palavra levaria à produção de um signo de qualidade e, assim, a "representação de objeto" a ela associada poderia tornar-se consciente.

Freud retoma, no Projeto, os conceitos de "representação de palavra" e de "representação de objeto" que haviam sido propostos em "Sobre a concepção das afasias", de 1891. A representação de palavra, de acordo com o que Freud propusera neste último texto, seria um complexo constituído por intrincado processo de associações, no qual estariam presentes quatro elementos: a imagem acústica, a imagem cinestésica da fala - ou glossocinestésica -, a imagem visual e a imagem cinestésica da escrita - ou quirocinestésica. A representação de objeto seria também um complexo associativo constituído por diversos tipos de imagens sensoriais. Ao falar sobre esse tipo de representação, Freud recorre à idéia de Stuart Mill, segundo a qual a representação de um objeto seria um complexo de impressões sensoriais, e a idéia de um objeto no mundo independente de nós seria uma crença resultante da "capacidade de expectativa" da mente humana, ou seja, a capacidade de, após ter sensações reais, concebermos que as mesmas sensações possam voltar a ser experienciadas, por nós e por outros, diante de determinadas condições e que outras sensações distintas possam ser acrescentadas às demais. Freud propõe que a ligação entre a representação de palavra e a de objeto se daria sempre entre a imagem acústica da primeira e, normalmente, a imagem visual da segunda, e propõe também que, ao menos no caso dos substantivos, é a representação de objeto que confere significado à representação de palavra.

No Projeto, ao se questionar sobre a possibilidade de uma representação ocupada pelo eu se tornar consciente, Freud retoma esses conceitos. Ele formula a hipótese de que, quando a ocupação de uma representação de objeto seguisse para a imagem acústica da palavra, e desta, para sua imagem cinestésica, seria produzida uma percepção, a 
qual levaria ao despertar de um signo de qualidade e, então, a representação de objeto poderia tornar-se consciente:

se as imagens de recordação forem de um tipo tal que uma corrente parcial possa ir delas para as imagens acústicas e para as imagens motoras da palavra, então a ocupação das imagens de recordação é acompanhada de notícias de descarga, as quais são signos de qualidade e, com isso, também signos de cons[ciência] da re[cordação]. (Freud, 1895/1950, p. 456)

Dessa forma, com a constituição das representações de palavra, os processos que ocorressem em $\psi$ como resultado da ação do eu poderiam alcançar a consciência, surgindo assim a possibilidade de rememoração. Portanto, enquanto houvesse apenas representações de objeto em $\psi$, os processos que aí ocorressem seriam inconscientes, com exceção dos que consistissem em eliminações motoras e em alucinação. Nessas últimas, a consciência seria imediata, ou melhor, decorreria única e diretamente das propriedades das percepções. Com a linguagem surgiria uma segunda forma de consciência, uma consciência mediata, isto é, intermediada pelos signos lingüísticos. Sendo assim, antes da constituição das associações lingüísticas, só seria possível pensamento consciente se este consistisse em uma ação. De fato, Freud afirma que o pensamento inicialmente consiste na ocupação de imagens de movimento e, embora ele não afirme explicitamente como a partir de um certo momento o pensamento e a ação chegam a diferenciar-se, é possível inferir que o que tornaria isto possível seria a constituição das associações da linguagem, as quais permitiriam que as ações fossem rememoradas e, assim, que não fosse mais preciso agir para pensar.

Uma vez que Freud, no Projeto, reconheceu explicitamente a natureza originariamente inconsciente do psiquismo, vejamos agora as conseqüências dessas hipóteses formuladas sobre a consciência para a noção de representação inconsciente ou, em outras palavras, para como passa a ser pensada, de agora em diante, a questão da relação entre a consciência e a representação.

\section{A relação entre representação e consciência}

Para que as representações pudessem ser rememoradas, seria necessário que elas estivessem associadas a uma representação de palavra; então, antes da constituição das associações lingüísticas, as representações de objeto seriam inconscientes e, assim, a inconsciência 
seria o estado originário das representações. Com a constituição dessas associações, parte das representações poderia tornar-se consciente, mas provavelmente algumas delas não seriam associadas a palavras, de modo que haveria um grupo de representações que permaneceria "insuscetível de consciência", utilizando o termo de Breuer (Freud \& Breuer, 1895). Outras representações poderiam também permanecer nesse estado, mesmo que chegassem a ser associadas a representações de palavras, devido ao bloqueio ou à interrupção dessa associação.

Portanto, haveria três tipos de representações inconscientes: aquelas associadas a representações de palavra, mas cujos signos de qualidade não fossem ocupados pelo eu ou não fossem despertados; aquelas que nunca foram associadas a representações de palavra; e aquelas cuja associação com a palavra estivesse impedida. No primeiro caso, embora inconscientes, as representações seriam "suscetíveis de consciência". No segundo e no terceiro casos, elas seriam "insuscetíveis de consciência". O último seria o caso das representações reprimidas responsáveis pela produção das neuroses. A representação inconsciente que estaria na origem dos sintomas neuróticos seria uma representação de objeto cuja associação com a representação de palavra estivesse bloqueada, para impedir sua rememoração e a conseqüente produção de desprazer dela resultante. Como disse Freud em O Inconsciente: "A representação não apreendida em palavras(...) fica então para trás, no interior do inconsciente, como algo reprimido" (1915, p.160). Dessa forma, já no Projeto... está presente a hipótese de que o inconsciente não coincide com o reprimido. ${ }^{9}$ As representações reprimidas, isto é, as que tivessem sua associação com a representação de palavra impedida, constituiriam apenas uma parte da totalidade das representações insuscetíveis de consciência, pois aquelas que não chegassem a ser associadas a representações de palavra também não poderiam tornar-se conscientes. Haveria, assim, um grupo de representações que permaneceria insuscetível de consciência, devido ao fato de nunca ter sido associado a

9 No Projeto estão presentes, pelo menos em esboço, uma teoria da dimensão pulsional do psíquico (a representação da estimulação endógena em $\psi$ do núcleo) e uma psicologia dos processos do eu, onde ambos aparecem como originariamente inconscientes, de modo que o inconsciente está longe de coincidir com o reprimido. A tópica exposta em "A interpretação dos sonhos" (1900) caracteriza-se por uma ampla restrição da problemática abarcada pelo Projeto, onde, entre outras coisas, a pulsão e o eu deixam de encontrar uma representação explícita no modelo do aparelho psíquico ali proposto. Desde esse ponto de vista, a tópica apresentada em "O eu e o isso" (1923) distingue-se pela retomada e pela reintegração na teoria do aparelho psíquico de pelo menos uma parte das questões postas entre parênteses após o Projeto - a instância pulsional (o isso), o eu e seu desdobramento narcísico (o ideal do eu, que originaria depois o supereu). 
representações de palavra, e um outro grupo cujo acesso à palavra existiu um dia, mas encontra-se atualmente impedido.

Em suma, segundo a teoria do Projeto, o campo da consciência seria restrito em relação ao da memória, e apenas uma parte das representações - aquelas que despertassem signos de qualidade e que tivessem esses signos ocupados pelo eu - se tornariam conscientes. A consciência seria, então, algo que poderia ou não se acrescentar a uma parte das representações. Antes da constituição das associações lingüísticas não haveria possibilidade de rememoração, a não ser de representações de movimento; portanto, até então só haveria consciência imediata, ou seja, resultante diretamente das propriedades da percepção. A constituição das representações de palavra traria consigo a possibilidade de uma segunda forma de consciência - uma consciência mediata - isto é, intermediada pelos signos lingüísticos. ${ }^{10}$ Como uma parte das representações de objeto possivelmente não chegaria a ser associada a representações de palavras, poderia haver representações que permanecessem sempre "insuscetíveis de consciência". Haveria também a possibilidade de um outro grupo de representações permanecer nesse estado, não por não ter sido associado a representações de palavras, mas por ter seu vínculo com a palavra bloqueado - este seria o caso das representações reprimidas. No Projeto, portanto, o campo das representações insuscetíveis de consciência não coincide com o reprimido.

Esse vínculo estabelecido por Freud entre a consciência e a palavra é retomado nos artigos metapsicológicos de 1915 praticamente no mesmo sentido em que foi proposto em 1895. Embora a tentativa de Freud de explicar as características dos processos materiais correlativos à consciência não tenha obtido pleno êxito, a partir do Projeto é possível compreender como a relação entre a consciência, a representação e a linguagem é pensada por Freud e como, correlativamente, a noção de representação inconsciente ganha espaço e contornos mais definidos em sua teoria.

\section{O problema da consciência na metapsicologia freudiana}

Quais as questões que se apresentam sobre o sentido da concepção freudiana da consciência tal como se depreende da apresentação de

10 Na carta 52, Freud chama essa consciência intermediada pela palavra de "consciência secundária". 
suas formulações no Projeto? Uma discussão desse tipo não é relevante somente para a compreensão desse texto, mas também do papel que a consciência deve vir a desempenhar na reflexão metapsicológica posterior, não apenas porque algumas de suas bases estavam certamente já lançadas em 1895, como também porque talvez Freud não tenha, em nenhum outro lugar, discutido com tanto detalhe e profundidade o problema da consciência. ${ }^{11}$

Uma primeira série de dificuldades parece provir da própria hipótese dos neurônios $\omega$. Esse sistema apresenta uma espécie de exceção ou parêntese no encaminhamento naturalista pretendido por Freud no Projeto: não permite nem mesmo as correlações anatômicas muito gerais estabelecidas para $\phi$ e $\psi$ (o sistema perifero-espinal e setores do córtex, respectivamente) e apresenta a capacidade excepcional de reagir ao período da excitação e não apenas à sua variação quantitativa. Quando consideramos a hipótese do período, fica patente a dificuldade de sustentar a necessidade da suposição do sistema $\omega$. Primeiro porque, se a qualidade provém do período, ela poderia perfeitamente originar-se em $\psi$; mesmo que a ocupação própria desse sistema seja "monótona", como pretende Freud, um processo perceptivo que aí se prolongue deveria, inevitavelmente, introduzir as variações que se traduzem em diferenças qualitativas. Por que a qualidade não se produz em $\psi$ ? Aparentemente, devido ao fato de que, aí, a intensidade da quantidade ainda é excessivamente grande para que o sistema seja sensível às diferenças de período, já que acima de um certo nível a quantidade traduz-se em sensações de desprazer, as quais como que cegam o sistema para a percepção de qualidades. Mas bastaria supor-se que, mesmo dentro de $\psi$, o processo excitatório experimenta, como o próprio Freud reconhece, um fracionamento progressivo que acabaria por produzir um nível de Q' $\eta$ compatível com o surgimento da qualidade. Isso permitiria consolidar a concepção da consciência como paralela a uma parte dos processos psíquicos em si inconscientes que constituem o sistema $\psi$, e não aos excepcionais processos $\omega$ cuja natureza não fica bem esclarecida. ${ }^{12}$

11 A não ser pelo provável artigo metapsicológico sobre a consciência, escrito por volta de 1915 e depois abandonado e perdido.

12 Por exemplo, se a questão da permeabilidade exigida pela percepção é satisfatoriamente resolvida pela hipótese do período - $\omega$ é permeável ao período, não à quantidade -, fica no entanto o problema de como as barreiras de contato são aí facilitadas, de modo a permitir a ocupação mínima do sistema e a descarga motora correspondente que Freud se vê obrigado a admitir, inclusive para poder sustentar a noção de "signos de qualidade". 
Em suma, a tese de que o sistema dos neurônios $\omega$ constitua a sede dos processos conscientes no âmbito do aparelho neuronal parece obstaculizar a formulação de uma concepção estritamente funcional da consciência que Freud nitidamente persegue em determinados momentos. De fato, uma concepção desse tipo se firma - a partir de "A interpretação dos sonhos", por exemplo - à medida que a hipótese do sistema $\omega$ se desvanece na teoria. Já na Carta 39, enviada para Fliess pouco depois da redação do Projeto (1.1.1896), o sistema $\omega$ aparece como um setor de $\psi$, justamente aquele setor onde a intensidade dos processos excitatórios torna-se menos intensa:

Os neurônios $\omega$ são aqueles neurônios $\psi$ suscetíveis de uma ocupação quantitativa muito escassa. A coincidência destas quantidades mínimas com a qualidade fielmente transferida a elas desde o órgão terminal é, de novo, a condição para a gênese da consciência. (Freud,1896, p. 437, grifos nossos) $)^{13}$

A idéia de um sistema próprio para os processos conscientes reaparecerá depois, de forma modificada, como o "sistema percepçãoconsciência" da tópica psíquica freudiana, mas então a ausência da referência neuronal, pelo menos de forma explícita, permitirá a Freud um considerável grau de omissão quanto à sua estrutura e sua organização, contribuindo para encobrir as dificuldades aqui apontadas.

Por outro lado, a distinção freudiana entre uma consciência imediata da percepção e uma consciência do pensamento mediada pela linguagem pode prestar-se a alguns mal-entendidos. Quando Freud afirma que, ao contrário do pensamento, a percepção traz consigo a qualidade, tendo portanto um acesso imediato à consciência, trata-se somente de ressaltar que, nesse caso, não é necessária a intervenção de nenhum fator externo à percepção para que ela possa fazer-se consciente, enquanto o pensamento, que inicialmente transita apenas entre representações de objeto e imagens de movimento, requer a intervenção da linguagem para tanto. Mas a percepção não é, ela própria, um processo imediato, no sentido de que aquilo que é apreendido pela cons-

13 Pribram e Gill (s./d., p. 81) consideram que, ainda no Projeto, $\omega$ é considerado como uma parte de $\psi$ : "nossa atenção se concentra primeira numa divisão de y que se torna o terceiro tipo de sistema neural descrito no Projeto. A razão imediata para o parcelamento de $\psi$ é a necessidade de um substrato que possa cuidar da qualidade (...)". Não nos parece, contudo, haver subsídios no texto do Projeto para sustentar essa divisão, a não ser que $\psi$ e $\omega$ têm que compartilhar o espaço anatômico do córtex cerebral, que é o que os autores parecem ter em mente. 
ciência seja um efeito direto ou exclusivo das propriedades do objeto externo, de modo que seja uma espécie de cópia do mesmo que se reproduz na experiência perceptiva. De fato, toda a reflexão freudiana sobre essas questões, desde seu passo inaugural em Sobre a concepção das afasias, vai na direção contrária dessa idéia, tendo pensado a constituição das representações como resultado de uma série de reorganizações dos processos neurais, que vai da recepção do estímulo sensorial num extremo ao surgimento de um fenômeno psíquico consciente no outro (a formulação do conceito de um inconsciente psíquico no Projeto... apenas atribuiu uma natureza mental a algumas etapas intermediárias deste processo). Assim, nesse caso ${ }^{14}$ a consciência seria consciência de uma representação em si inconsciente e, quando se trata da percepção, a qualidade que torna essa consciência possível é inerente ao processo e, portanto, pode ser dita "imediata", mas a formação da representação não é, ela mesma, imediata, no sentido de que não resulta diretamente da impressão externa.

Essa perspectiva é reforçada quando, após o Projeto..., Freud empreende o desdobramento do sistema $\psi$ numa série de subsistemas definidos por diferentes princípios de organização, o que irá culminar no modelo espacialmente orientado de A interpretação dos sonhos. A concepção jacksoniana de uma atividade neural estruturada numa série de sistemas e modos de organização hierarquicamente superpostos, que vai do mais arcaico, simples e rígido ao mais evoluído, complexo e flexível, é transposta por Freud para a própria organização interna da atividade cortical, ou seja, para aquilo que, do ponto de vista psicológico, pode ser descrito como representação. A partir daí, o processo psíquico deixa definitivamente de ser o concomitante do último elo da cadeia dos processos neurais e passa a ser concebido como, digamos, todo o último andar da estrutura desses processos, divisível, por sua vez, numa seqüência de sistemas que descrevem as formas de organização do material representacional constituídas ao longo do desenvolvimento do indivíduo, progressivamente mais complexas, mais evoluídas (no sentido ontogenético), ${ }^{15}$ até que, no extremo dessa arquitetura neuropsicológica, tornem-se possíveis o pensamento e a percepção conscien-

14 O outro caso seria a consciência das sensações de prazer e desprazer e, mais genericamente, a dos afetos e sentimentos.

15 Para Hughlings Jackson (1884), a estrutura dos centros nervosos estende-se da periferia sensóriomotora ao córtex e reflete a evolução filogenética que torna possível processos que vão do puro reflexo, num extremo, ao pensamento consciente, o movimento voluntário e a linguagem proposicional, no outro. Jackson emprega a noção de representação (representation) - de que Freud 
tes e o movimento voluntário. Dessa maneira, a consciência deixa de ser um sistema dotado de características próprias e exclusivas - o sistema $\omega$ do Projeto... -, para converter-se em uma propriedade que se acrescenta aos processos neuropsíquicos a partir de uma certa etapa e de um certo grau de sua organização, de sua complexidade e de sua evolução (onto e filogenética). Essa tendência se acentuará quando, com a dissolução da noção de um sistema inconsciente na passagem para a segunda tópica, Freud passar a referir-se a "inconsciente" e "consciente" como qualidades psíquicas, ou seja, como propriedades dos processos, mas não mais, necessariamente, como classes de processos homogêneos. Quanto à percepção, observe-se que, desde "A interpretação dos sonhos", fica claro, pela própria estrutura do aparelho, que o estímulo recebido pela extremidade perceptiva do mesmo, deve atravessá-lo na sua integridade, ser submetido a toda a série de transcrições e reorganizações, antes que possa tornar-se conscientes na extremidade oposta. Talvez o indicador mais nítido de como Freud pensa a percepção consciente como possibilitada por esse processo complexo de organização do material sensorial bruto seja o modo como ele aplica o conceito de elaboração secundária, ${ }^{16}$ não apenas à alucinação onírica, mas à atividade perceptiva como tal:

A culminação do processo do sonho dá-se quando o conteúdo de pensamento, regressivamente transformado e retrabalhado como uma fantasia de desejo, torna-se consciente como percepção sensorial, com o que experimenta a elaboração secundária à qual todo conteúdo perceptivo é submetido. (Freud, 1917, p. 186, grifos nossos)

Em suma, a consciência da percepção depende, tanto quanto qualquer outro processo, da organização do material segundo os princípios

\footnotetext{
lança mão em Afasias..., opondo-a à projeção de Meynert - para designar a relação entre os diversos níveis de processos (ele fala de uma representação, de uma re-representação e de uma re-rerepresentação dos mesmos). Freud transpõe essa noção, a partir da Carta 52, para a relação entre os sistemas psíquicos, como que a reforçar a idéia de que a representação não é a cópia de um objeto, mas o último estágio de um processo de reorganização dos dados sensoriais oriundos da periferia do sistema nervoso. Pode-se dizer que, com isso, Repräsentation (o termo empregado em Afasias... para traduzir o conceito de Jackson) e Vorstellung se identificam em parte ou, pelo menos que a segunda passa a ser um caso particular da primeira.

16 A elaboração secundária (sekundäre Bearbeitung) é a última etapa do trabalho do sonho, que introduz um mínimo de coerência no material onírico, de modo que ele possa ser rememorado conscientemente durante a vigília e posto sob a forma do relato verbal. É, por assim, dizer, uma adaptação parcial dos processos do sonho às formas do pensamento consciente (ou pré-consciente), organizadas pela linguagem.
} 
que regem a edificação das instâncias do aparelho psíquico, ${ }^{17}$ embora Freud não tenha alcançado a formulação de uma teoria plenamente satisfatória do Bewußtwerden, restando ainda uma ampla lacuna na explicação de como os processos psíquicos acedem à consciência e, no limite, na elaboração de um conceito definido desta última.

Com efeito, de ponta a ponta de sua obra, desde o momento mesmo em que rompeu com a identificação entre o psíquico e o consciente de que se vangloriará depois, a consciência converte-se em um problema para a metapsicologia edificada por Freud, talvez até mesmo num problema insolúvel, pelo menos nos termos em que se encontra ali formulado. No Projeto, Freud abre a seção sobre a consciência reconhecendo a lacuna explicativa que se estende entre esta e as hipóteses neuropsicológicas construídas para justificá-la: "Não se pode naturalmente tentar dar uma explicação sobre como processos excitatórios nos neurônios $\omega$ trazem consigo a consciência" (p. 403, grifos nossos). No outro extremo de sua obra, no "Esboço de psicanálise" (1938), podemos ler:

O ponto de partida para essa indagação é dado pelo fato da consciência, fato incomparável, que desafia toda tentativa de explicá-lo e descrevê-lo. E, no entanto, se se fala de consciência, sabe-se de maneira imediata o que se quer dizer com isso. (p. 155, grifos nossos)

Essa passagem pode ser considerada uma espécie de reconhecimento final dos impasses a que chegou o encaminhamento dado por Freud ao problema da consciência. A aposta numa psicologia naturalista - a única aceitável segundo o ideário epistemológico freudiano - pareceu esbarrar na impossibilidade de uma naturalização da consciência, a qual, no entanto, contradiz a determinação de que uma psicologia completa deve, obrigatoriamente, dela se ocupar. Não há, enfim, uma metapsicologia freudiana da consciência, a não ser talvez como um programa de investigação ainda consideravelmente indefinido, restando decidir se a impossibilidade de sua abordagem nesses termos é definitiva ou provisória. É dessa impossibilidade que deve se ocupar qualquer

17 Que o conteúdo perceptivo como um todo está submetido à elaboração secundária já havia sido reconhecido por Freud na Traumdeutung (1900): "Nosso pensamento desperto (pré-consciente) se comporta diante de um material perceptivo qualquer exatamente como a função em questão [a elaboração secundária] diante do conteúdo do sonho. Compete-lhe, certamente, colocar em ordem esse material, estabelecer relações e adequá-lo à expectativa de uma concatenação inteligível" (p. 480). 
avaliação dos limites da metapsicologia freudiana sobre este tópico específico, se se quiser medir a eficácia de sua estratégia explicativa segundo seus próprios parâmetros e, ao mesmo tempo, criar condições para vislumbrar o caminho pelo qual os impasses que se opõem à formulação de uma concepção naturalista da consciência poderiam ser superados. O fracasso freudiano nesse ponto, contudo, não chega a ser particularmente desabonador. A via para a consecução desses objetivos e para a superação desses impasses, no que se refere à consciência, é uma coisa que o desenvolvimento contemporâneo da psicologia e mesmo o das chamadas ciências cognitivas - o mais amplo e aparentemente bem sucedido projeto de naturalização do mental - está longe de ter demonstrado de forma inequívoca.

\section{Agradecimentos}

Richard T. Simanke deseja agradecer ao CNPq pelo apoio concedido, sob a forma de Bolsa de Produtividade em Pesquisa, ao projeto "Consciência e representação em psicanálise: alcance e limites da reflexão metapsicológica", ao qual o presente trabalho encontra-se relacionado.

SIMANKE, R. T. \& CAROPRESO, F. S. The concept of consciousness in Freud's Project for a psychology and its metapsychological consequences. Trans/ Form/Ação, (São Paulo), v.28(1), 2005, p.85-108.

- ABSTRACT: Freud's Project for a psychology (1895) presents a wide reflection on the concept of consciousness, which, in spite of certains difficulties, casts some light on how Freud then conceived the relations between consciousness, representation and language. The aim of this paper is to circumscribe the meaning of the concept of consciousness found in the Project for a psychology and to discuss some of its consequences for the way consciousness is approached later in Freudian metapsychology.

- KEYWORDS: Freud; metapsychology; representation; consciousness; language.

\section{Referências bibliográficas}

FREUD, S. (1891). Zur Auffassung der Aphasien: eine kritische Stuudie. Frankfurt am Main: Fischer Taschenbuch Verlag, 1992. 173 p. 
FREUD, S. (1894). Die Abwehr-Neuropsychosen. Versuch einer psychologischen Theorie der akquirierten Hysterie, vieler Phobien und Zwangvorstellungen und gewisser halluzinatorischer Psychosen. Gesammelte Werke. Ersten Band. London: Imago, 1952. p. 57-74. . (1895/1950) Entwurf einer Psychologie. Gesammelte Werke. Nachtragsband. Frankfurt am Main: S. Fischer Verlag, 1987. pp. 373-486.

Die Traumdeutung. Studienausgabe, Band II. Frankfurt am Main: Fischer Taschenbuch Verlag, 1982.

(1915) Das Unbewusste. Studienausgabe, Band III. Frankfurt am Main: Fischer Taschenbuch Verlag, 1982. pp. 119-73. (1920) Jenseits des Lustprinzips. Studienausgabe, Band III. Frankfurt am Main: Fischer Taschenbuch Verlag, 1982. pp. 213-72.

(1923) Das Ich und das Es. Studienausgabe, Band III. Frankfurt am Main: Fischer Taschenbuch Verlag, 1982. pp. 273-330.

(1938) Esquema del psicoanálisis. Sigmund Freud: Obras Completas, vol. XXIII. Buenos Aires: Amorrortu Editores, 1998. pp. 133-209.

FREUD, S. \& BREUER, J. (1895) Estudios sobre la histeria. Obras Completas, vol.II. Buenos Aires: Amorrortu Editores, 1998.

JACKSON, J. H. (1884) Evolution and dissolution of the nervous system. Select Writings of John Hughlings Jackson, vol.II. New York: Basic Books, 1958, pp. 45-75.

PRIBRAM, K \& GILL, M. O Projeto de Freud: um exame crítico. São Paulo: Cultrix, s./d. $179 \mathrm{p}$.

STRACHEY, J. (1975). Appendix C: The nature of Q. The standard edition of the complete psychological works of Sigmund Freud. London: The Hogarth Press and the Institute of Psycho-Analysis, vol. 1, 1975, pp. 392-7. 